\title{
Comparison of diagnostic methods for hemodynamic treat- ment in unborn and preterm infants using the measurement of vena cava, lactate, and clinical criteria.
}

\section{Geyson Deley-M uñoz ${ }^{1}$, Fabricio González-Andrade,*12@}

1 College of Health Sciences, Universidad San Francisco de Quito. Quito, Ecuador.

2. Unit of Translational Medicine, Faculty of Medical Sciences, Universidad Central del Ecuador, Quito, Ecuador.

Received:April 2, 2021

Accepted: September 17,2021

Published: December 1, de 2021

Bibliographic letterhead:

Deley-Muñoz G, González-Andrade F. Comparison of diagnostic methods for hemodynamic treat-mentin unborn and preterm infants using the measurement of vena cava, lactate, and clinical criteria. Revista Ecuatoriana de Pediatría 2021;22(3):Article 18:1-9 doi: https:// doi.org/ 10.52011/ 81

Copyright Deley-Muñoz G, et al. This article is distributed under the terms of Creative Commons attribution license CC BY-NC-SA 4.0, which allows the use and redistribution citing the source and the original author without commercial purposes.

\section{Abstract}

Introduction: There is no single criterion available to assess the hemodynamic state of newbom infants and preterm infants and the different variables in the group of newborns, such as gestational age, birth weight, and periods of birth.

Methods: This is an epidemiological, cross- sectional, descriptive observational study with two patient cohorts. Newbom- to- term and preterm neonates assisted at the Neonatal Unit of the Pablo Arturo Suarez Hospital participated during the months between November 2019 to January 2020.

Results: Ultrasound measurement of the vena cava (FVC) flow is useful for the management treatment of hemodynamically unstable neonatal patients. The sample was made up of 110 newborns treated in the Pablo Arturo Suarez Hospital's neonatology service from November 2019 to January 2020. Quito, Pichincha, Ecuador. The variables low birth weight and moderate prematurity have a statistically significant value for inotropic use. The other variables do not present statistically significant values. Heart rate, urinary output, mean blood pressure, la ctic acid, capillary filling, upper vena cava flow, and lower vena cava flow had statistically significant values. $\mathrm{FVCl}$ and FVCS comparisons with heart rate, urinary output, mean blood pressure, lactic acid, and capillary filling had statistically significant values, except for capillary filling $>3$ sec in FCV. Multivariate analysis of categorical main components (CATPCA) was used to characterize the hemodynamic state and inotropic state, which were significant in the bivariate analysis. Dimension, one of the two- dimensional graphs, discriminates the use or not of inotropics and the categories of hemodynamic parameters TAM $<35 \mathrm{mmHg}$, lactic acid, capillary filling, $\mathrm{FVCl}$, and FVCS. Dimension two discriminates between the categories of urinary expenditure and $\mathrm{HR}$.

Conclusion: In term and preterm infants with low weight and adequate birth weight with hemodynamic instability in general, who were evaluated with ultrasonography to measure the flow of the vena cava, the agreement between the clinical criteria and the ultrasound assessment of the flow was $0.4 \mathrm{~cm} / \mathrm{sec}$ in both methods. This situation means that the measurement of venous cava flows by echo sonography is useful for assessing neonatal patients' hemodynamic status.

\footnotetext{
* Corresponding autor

E-mail: fa briciogonza leza @gmail.com (Fabricio Gonzalez And rade) / Iquique N14-121ySodiro-Itchimbía, 170403, Quito, Ecuador.
} 
Keywords: neonate, hemodynamic, lactate, blood pressure, capillary refill, heart rate, hourly diuresis, flow vena cava.

\section{Introduction}

Maintaining the hemodynamic state requires adequate blood pressure, vascular resistance, and tissue perfusion [1]. These variables are influenced by gestational age, birth weight, adequate extrauterine adaptation, drugs, or adequate maternal hemodynamics; therefore, specifying normality only with clinical criteria is problematic. The normal physiological range of blood pressure is unknown in both premature and term infants [2]. Blood pressure is the product of the flow due to systemic vascular resistance, and the flow is dependent on preload, contractility, systolic volume, and afterload, so that the drop in blood pressure may be secondary to low expenditure cardiac, low vascular resistance, or both $[\underline{3}, \underline{4}]$.

Newborn hemodynamic surveillance often includes blood pressure, urine output, heart rate, capillary filling, and lactic acid, which have numerous limitations and are only variables dependent on tissue perfusion $[\underline{5}, \underline{6}]$. The newborn can present various hemodynamic problems whose pathophysiology is complex as a variable and sometimes little predictable after clinical assessment. Therefore, the interpretation of these parameters can lead to erroneous conclusions and the adoption of incorrect therapeutic strategies in unstable patients [7]. Functional echocardiography for evaluating venous flows is a hemodynamic evaluation technique added to regular monitoring to guide the clinician in his therapeutic interventions in the neonatal intensive care unit $[\underline{8}, \underline{9}]$.

The role of echocardiography in neonatal intensive care units was intended to be performed by the pediatric cardiologist and used only for the diagnosis and control of congenital heart disease. Currently, neonatologists who have been interested in the echocardiographic evaluation of hemodynamic instability, given that it is a dynamic assessment with a noninva sive method that provides complementary information to the clinic and in real time, becomes essential for the adequate and more appropriate management of newborns in critical condition [ $\underline{\underline{D}}-\underline{\underline{D}}]$.
The first compensatory mechanism for extrauterine adaptation is the increase in chronotropism due to poor inotropism due to an immature myocardium and poorly sensitive receptors, so the use of vasoactive drugs that help maintain peripheral vascular resistance and preload is sustained to maintain adequate cardiac output accompanied by expected urine output and without lactic acid production. Under conditions of hemodynamic instability, the drop in peripheral vascular resistance promotes oliguria, and anaerobic metabolism increases the production of lactic acid, lowering the mean arterial pressure and prolonging capillary filling. As a result, these factors cause the chronotropic response to not compensate for the needs, so vasoactive drugs are needed to restore their function, an event that can be immediately identified, and respond to their treatment by measuring the flow of the vena cava [ $\underline{\underline{B}}-\underline{16}]$.

\section{Methods}

\section{Research design}

This is a cross-sectional, epidemiological, and observational study of 2 cohort groups.

\section{Location}

Neonatology Service of the Pablo Arturo Suarez Hospital, data collection from November 2019 to January 2020.

\section{Inclusion/ exclusion criteria}

All newborns of both sexes, at term and preterm born at the Pablo Arturo Suarez Hospital, with hemodynamic alteration (heart rate greater than $\mathbf{1 8 0}$ bpm or less than $\mathbf{1 0 0} \mathrm{bpm}$, capillary filling more generous tha $\mathrm{n}$ 3 seconds, diuresis less than $1 \mathrm{ml} / \mathrm{kg} / \mathrm{h}$, lactate more significant than $1 \mathrm{mg} / \mathrm{dL}$, Mean Arterial Tension less than $35 \mathrm{~mm}$

Exclusion criteria were all newborns at term and preterm who were not born at the Pablo Arturo Suarez Hospital and patients without hemodynamic alteration. 
Elimination criteria were newborns in the variable data that were incomplete, inconsistent, or inconsistent and newborns whose mothers did not consent to their child being part of the study.

\section{Study Size}

10 individuals, 55 to terms and 55 preterms.

\section{Statistical method}

Statistical analyses were performed with the statistical package IBM SPSS version 25, and descriptive statistics were used, using tables representing the absolute and relative frequencies of the qualitative variables. In inferential statistics, bivariate analyses were performed. For the qualitative variables where proportions were compared, the chi-square test was used. For the quantitative variables, the t-test of independent samples was used since the FVCI and FVCS variables presented a normal distribution. For the multivariate analysis, categorical main components (CMC) were used. Statistical significance to compare proportions and means was established for a $P$-value $\measuredangle 0.05$.

\section{Results}

Ultrasound measurement of the Vena Cava flow (FVC) flow is useful for managing hemodynamically unstable neonatal patients; the sample was made up of 110 newborns treated in the neonatology service Pablo Arturo Suarez Hospital from November 2019 to January 2020. Quito-Pichincha - Ecuador.

Table 1shows that the variables low birth weight and moderate prematurity have a statistically significant value for inotropic use. The other variables do not present statistically significant values. Table 2 shows the variables heart rate, urinary output, mean blood pressure, lactic acid, capillary filling, upper vena cava flow, and lower vena cava flow, which had statistically significant values. Table 3 shows that FVCI and FVCS comparisons with heart rate, urinary output, mean blood pressure, lactic acid, and capillary filling had statistically significant values, except for capillary filling $>3$ sec FCV.

Graphic 1shows that the multivariate analysis of categorical main components (CMC) was used to characterize hemodynamic and inotropic use, which were significant in the bivariate analysis. Dimension, one of the two-dimensional graphs, discriminates the use or not of inotropics and the categories of hemodynamic parameters TAM $<35 \mathrm{mmHg}$, lactic acid, capillary filling, $\mathrm{FVCl}$, and FVCS. Dimension two discriminates between the categories of urinary expenditure and HR.

Table 1Distribution of the characteristics of neonates regarding the use of inotropics

\begin{tabular}{|c|c|c|c|c|}
\hline \multirow{2}{*}{ Neonate characteristic } & \multirow{2}{*}{ Total } & \multicolumn{2}{|c|}{ Inotropic use } & \multirow{2}{*}{$P$} \\
\hline & & Yes & No & \\
\hline \multicolumn{5}{|l|}{$\operatorname{Sex}\left(\mathrm{n}(\%)^{y}\right.$} \\
\hline Male & $52(47.27)$ & $35(67.31)$ & $17(32.69)$ & \\
\hline Female & $58(52.73)$ & $33(56.90)$ & $25(43.10)$ & 0.262 \\
\hline Gestational age $(\operatorname{mean}(\mathrm{SD}))^{2 /}$ & $37(2)$ & $36(3)$ & $37(2)$ & 0.272 \\
\hline Birth weight (mean (SD) $)^{2 /} \mathrm{gr}$ & $2.452(509)$ & $2.377(510)$ & $2.575(488)$ & $0.047 * *$ \\
\hline \multicolumn{5}{|l|}{ Low birth weight $\left(\mathrm{n}(\%)^{y}\right.$} \\
\hline Yes & 65 (59.09) & $42(64.62)$ & $23(35.38)$ & \multirow{2}{*}{0.468} \\
\hline No & $45(40.91)$ & $26(57.78)$ & $19(42.22)$ & \\
\hline \multicolumn{5}{|l|}{ Preterm $\left(n(\%)^{y}\right.$} \\
\hline Yes & $58(52.73)$ & $38(65.52)$ & $20(34.48)$ & \multirow{2}{*}{0.399} \\
\hline No & $52(47.27)$ & 30 (57.69) & $22(42.31)$ & \\
\hline \multicolumn{5}{|l|}{ Preterm category $\left(\mathrm{n}(\%)^{y}\right.$} \\
\hline Mild & $31(53.45)$ & 16 (5161) & $15(48.39)$ & \multirow{2}{*}{$0.017 *$} \\
\hline Moderate & $27(46.55)$ & $22(8148)$ & $5(18.52)$ & \\
\hline \multicolumn{5}{|c|}{ Maternal hemodynamic changes $\left(\mathrm{n}(\%)^{y}\right.$} \\
\hline Yes & $71(65.14)$ & $48(67.61)$ & 23 (32.39) & \multirow{2}{*}{0.072} \\
\hline No & $38(34.86)$ & $19(50.00)$ & $19(50.00)$ & \\
\hline
\end{tabular}


In quadrants II and III, it was observed that the use of ino-tropics was associated with $\mathrm{FVCl}<0.40$, FVCS $<0.40$, TAM $<35 \mathrm{mmHg}$, lactic acid $>1 \mathrm{mmol} / \mathrm{L}$, and capillary filling $>3 \mathrm{sec}$, while in quadrant $\mathrm{I}$, the nonuse of inotropics was related to $\mathrm{FVCl}>0.40$ and $\mathrm{FVCS}>0.40$ in the absence of TAM $<35 \mathrm{mmHg}$ and lactic acid $<1$ $\mathrm{mmol} / \mathrm{L}$

Table 2. Distribution of the characteristics of the hemodynamic state of neonates concerning the use or not of inotropics

\begin{tabular}{|c|c|c|c|c|}
\hline \multirow{2}{*}{ Characteristics of the Hemodynamic state } & \multirow{2}{*}{ Total } & \multicolumn{2}{|c|}{ Inotropic use } & \multirow[b]{2}{*}{$P$} \\
\hline & & Yes & Yes & \\
\hline \multicolumn{5}{|l|}{ Heartrate $\left(\mathrm{n}(\%)^{7}\right.$} \\
\hline$>180$ & $86(82.69)$ & $48(55.81)$ & 38 (44.19) & \multirow{2}{*}{$<0.000 \mathbb{1}^{*}$} \\
\hline$<100$ & 18 (17.31) & $18(100.00)$ & $0(0.00)$ & \\
\hline \multicolumn{5}{|l|}{ Urinary output $(\mathrm{n}(\%))^{y}$} \\
\hline$>1 \mathrm{ml} / \mathrm{kg} / \mathrm{h}$ & $96(87.27)$ & $54(56.25)$ & $42(43.75)$ & \multirow{2}{*}{$<0.0001^{*}$} \\
\hline$<\mathrm{lml} / \mathrm{kg} / \mathrm{h}$ & $14(12.73)$ & $14(100.00)$ & $0(0.00)$ & \\
\hline \multicolumn{5}{|l|}{ Mean Blood Pressure $<35 \mathrm{mmHg}\left(\mathrm{n}(\%)^{y}\right.$} \\
\hline Yes & 65 (59.09) & 60 (92.31) & $5(7.69)$ & \multirow{2}{*}{$<0.000 \mathbb{1}^{*}$} \\
\hline No & $45(40.91)$ & $8(17.78)$ & $37(82.22)$ & \\
\hline \multicolumn{5}{|l|}{ Lactic acid $\left(\mathrm{n}(\%)^{y}\right.$} \\
\hline$<1 \mathrm{mmol} / \mathrm{L}$ & $21(19.44)$ & $5(23.81)$ & $16(76.19)$ & \multirow{2}{*}{$<0.000 \mathbb{1}^{*}$} \\
\hline$>1 \mathrm{mmol} / \mathrm{L}$ & $87(80.56)$ & $63(72.41)$ & $24(27.59)$ & \\
\hline \multicolumn{5}{|l|}{ Capillar filling $>3 \operatorname{seg}(n(\%))^{y}$} \\
\hline Yes & $44(40.00)$ & $34(77.27)$ & $10(22.73)$ & \multirow{2}{*}{$0.006^{*}$} \\
\hline No & $66(60.00)$ & $34(5152)$ & $32(48.48)$ & \\
\hline $\mathrm{FVCl}(\operatorname{mean}(\mathrm{SD}))^{2 /}$ & $0.35(0.14)$ & $0.27(0.09)$ & $0.46(0.13)$ & $<0.0001^{k *}$ \\
\hline $\operatorname{FVCS}(\text { mean (SD) })^{2 /}$ & $0.37(0.17)$ & $0.31(0.14)$ & $0.48(0.17)$ & $<0.0001^{*} *$ \\
\hline \multicolumn{5}{|l|}{$\mathrm{FVCl}\left(\mathrm{n}(\%)^{y}\right.$} \\
\hline$<0.40$ & $66(60.00)$ & $57(86.36)$ & $9(13.64)$ & \multirow{2}{*}{$<0.0001^{*}$} \\
\hline$\geq 0.40$ & $44(40.00)$ & $11(25.00)$ & $33(75.00)$ & \\
\hline \multicolumn{5}{|l|}{$\operatorname{FVCS}\left(\mathrm{n}(\%)^{y}\right.$} \\
\hline$<0.40$ & $58(52.73)$ & 50 (86.21) & $8(13.79)$ & \multirow{2}{*}{$<0.0001^{*}$} \\
\hline$\geq 0.40$ & $52(47.27)$ & $18(34.62)$ & $34(65.38)$ & \\
\hline
\end{tabular}

NoteSD =StandardDeviation; $1 /$ based on the chi-square statistic homogeneity test* significant differences in the proportion of use of inotropic $p$-value $<0.05 ; 2$ / based on the t-test of independent samples. ** significant differences in the means between the use or not of inotropic $p$-value $<0.05$. FVCl: Lower vena cava flow. FVCS: superior vena cava flow

Table 3. Comparison of FVCl and FVCS regarding the characteristics of the hemodynamic state.

\begin{tabular}{|c|c|c|c|c|}
\hline \multirow{2}{*}{ Characteristics of the Hemodynamic state } & \multicolumn{2}{|c|}{$\mathrm{FVCl}$} & \multicolumn{2}{|c|}{ FVCS } \\
\hline & Mean (SD) & $P$ & Mean (SD) & $P$ \\
\hline \multicolumn{5}{|l|}{ Heartrate $\left(\mathrm{n}(\%)^{\eta}\right.$} \\
\hline$>180$ & $0.36(0.15)$ & \multirow{2}{*}{$<0.0001^{*}$} & $0.39(0.17)$ & \multirow{2}{*}{$0.009 *$} \\
\hline$<100$ & $0.26(0.07)$ & & $0.28(0.14)$ & \\
\hline \multicolumn{5}{|l|}{ Urinary output $(\mathrm{n}(\%))^{y}$} \\
\hline$>1 \mathrm{ml} / \mathrm{kg} / \mathrm{h}$ & $0.36(0.15)$ & \multirow{2}{*}{$<0.0001^{*}$} & $0.38(0.17)$ & \multirow[t]{2}{*}{$0.024^{*}$} \\
\hline$<\mathrm{lml} / \mathrm{kg} / \mathrm{h}$ & $0.26(0.07)$ & & $0.30(0.11)$ & \\
\hline \multicolumn{5}{|l|}{ Mean Blood Pressure $<35 \mathrm{mmHg}\left(\mathrm{n}(\%)^{y}\right.$} \\
\hline $\begin{array}{l}\text { Yes } \\
\text { No }\end{array}$ & $0.28(0.17)$ & \multirow[t]{2}{*}{$<0.0001^{*}$} & $0.31(0.14)$ & $<0.0001$ \\
\hline \multicolumn{4}{|l|}{ Lactic acid $\left(\mathrm{n}(\%)^{y}\right.$} & \\
\hline $\begin{array}{l}<1 \mathrm{mmo} / \mathrm{L} \\
>1 \mathrm{mmol} / \mathrm{L}\end{array}$ & $\begin{array}{l}0.41(0.14) \\
0.32(0.14)\end{array}$ & $0.01 \mathbb{1}^{*}$ & $\begin{array}{l}0.47(0.17) \\
0.34(0.16)\end{array}$ & $0.003^{*}$ \\
\hline \multicolumn{5}{|l|}{ Capillar filling $>3 \operatorname{seg}(n(\%))^{y}$} \\
\hline $\begin{array}{l}\text { Yes } \\
\text { No }\end{array}$ & $\begin{array}{l}0.31(0.15) \\
0.36(0.14)\end{array}$ & 0.054 & $\begin{array}{l}0.32(0.17) \\
0.41(0.16)\end{array}$ & $0.008^{*}$ \\
\hline
\end{tabular}

Note DE = Standard Deviation; based on the t-test of independent samples. ** Significant differences in the means of FVCI or FVCS p-value $<0.05$. FVCl: Lower vena cava flow. FVCS: superior vena cava flow. 


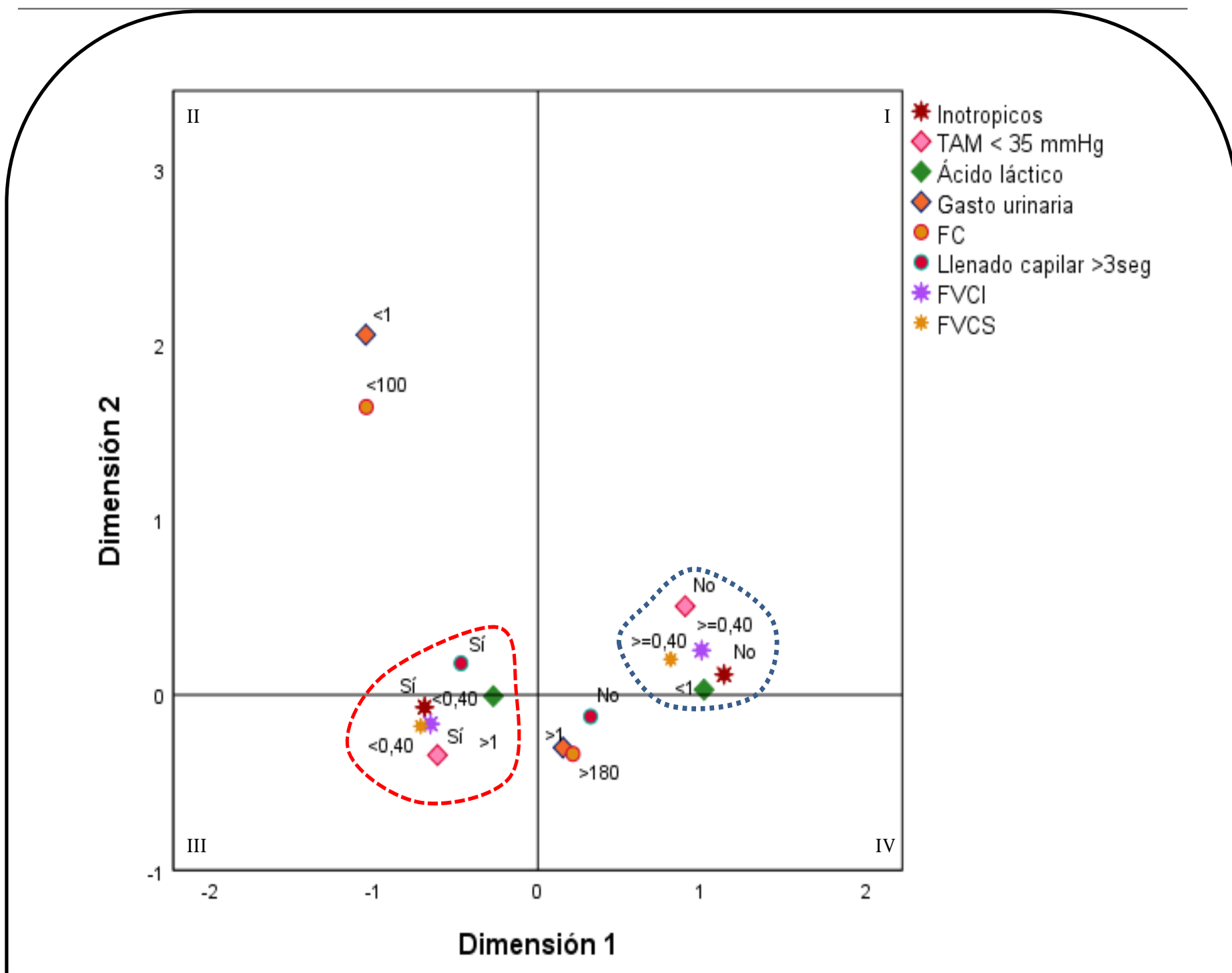

Fig. 1 Multivariate relationship of hemodynamic state parameters and inotropic use.

Note: Based on the multivariate analysis of categorical main components (CMC). FVCI: Lower vena cava flow. FVCS: superior vena cava flow

\section{Discussion}

Regarding the characteristics of neonates, it was found that low birth weight had a statistically significant value for the use of inotropics. The transition explains this from foetal to neonatal circulation, which is slower and is associated with circulatory modifications when transferring the gas exchange of the placenta to the lungs along with the slow morphological development of the receptors $[\underline{4}, \underline{5}]$. Cardiac fetal development does not show differences between sexes, so neonatal adaptation occurs equally. Testosterone has a more significant hypertrophic effect at an older age by developing arteries of better caliber, while progesterone and estrogens have a more significant hyperplastic effect [ $[\underline{6}, \underline{7}]$.

Gestational age is directly proportional to cardiac function and a slow adaptation to transition; low cardiac output is due to low peripheral vascular resistance [8].

Regarding the hemodynamic state characteristics and inotropic use, the increase in chronotropism is the 
first compensatory mechanism due to poor inotropism due to an immature myocardium and poorly sensitive receptors, noting the need for inotropics [9]. Adequate cardiac output ensures adequate urinary expenditure, but in shock conditions, the fall in peripheral vascular resistance promotes oliguria by not maintaining adequate perfusion of the renal arteries needing vasoactive drugs to restore their function. In the neonatal period, high pulmonary vascular resistance falls under optimal adaptation conditions, allowing the left ventricle to have normal function. However, in any hemodynamic alteration, its persistence promotes the decrease of the mean arterial pressure mediated by inadequate response to oxygen, prostaglandins, and changes in the endothelium vascular, making clear the requirement of inotropic $[\underline{1}, \underline{1]}$.

Lactic acid is a biochemical marker of anaerobic metabolism and is an indicator of cytopathic hypoxia attributed to myocardial function's inadequate response, translated into low mean blood pressure $[\underline{\underline{D}}$, 13]. Capillary filling as an indicator of distal perfusion controlled by the vascular endothelium and peripheral vascular resistance indirectly denotes hemodynamic

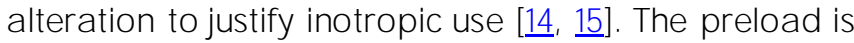
directly proportional to the systolic volume by projecting adequate cardiac output. Sonographically, the Doppler measurement of the velocity or flow through the venous veins indicates good hydrodynamics, resulting in the direct and dynamic assessment of the hemodynamic state, a fundamental contribution to the use. of inotropic $[\underline{1}, \underline{1}]$ ].

Tachycardia is related to increased parasympathetic and beta-adrenergic activity as compensation, and increasing the minute volume increases the preload and therefore translates into the altered flow of veins [푸] . The umbilical impingement produces an increase in renal blood flow due to the decrease in renal vascular resistance and the increase in systemic arterial pressure favoring glomerular filtration; if the transition due to a hemodynamic alteration is not adequate, low urinary expenditure and not increasing systemic pressure Cava flows are also altered $[\underline{18}, \underline{19}]$.

The increase in lactic acid due to anaerobic metabolism results in vasodilation with the consequent decrease in mean arterial pressure that alters vena cava flow. Venous vein flow is controlled by an adequate preload and peripheral vascular resistances; if titular perfusion drops, capillary filling is prolonged due to the inadequate production of endothelial nitric oxide from the flow of the cava [9].

The absence of TAM less than $35 \mathrm{mmHg}$, lactic acid greater than $1 \mathrm{mmol} / \mathrm{L}$, capillary filling greater than 3 seconds, and alteration of FVC discriminate the use of inotropics because the compensatory mechanisms are given by the autonomic nervous system, chronotropism, vascular endothelium, and peripheral vascular resistance to maintain homeostasis, allowing the flow of cava veins to be disturbed $[\underline{2}, \underline{\underline{10}}-\underline{20}]$.

\section{Conclusions}

In term and preterm infants with low weight and adequate birth weight with hemodynamic instability in general, who were evaluated with ultrasonography to measure the flow of the vena cava, the agreement between the clinical criteria and the ultrasound assessment of the flow was $0.4 \mathrm{~cm} / \mathrm{sec}$ in both methods. This situation means that the measurement of venous cava flows by echo sonography is useful for assessing neonatal hemodynamic patients.

\section{Abbreviations}

CMC. categorical main components. FVCl: Lower vena cava flow. FVCS: superior vena cava flow

\section{Supplementary information}

Supplementary materials are not declared.

\section{Acknowledgments}

We acknowledge and thankthe authorities of the Pablo Arturo Suárez Hospital who facilitated the study.

\section{Authors' contributions}

Geyson Deley-M uñoz: Conceptualization, Data Conservation, Fund Acquisition, Research, Resources, Software, Writing - Original Draft, Writing: Review and Editing.

Fabricio González-Andrade: Methodology, Formal analysis, Project management, Supervision, Validation, Visualization.

\section{Financing}

The authors financed the expenses incurred in the production of this research.

\section{Availability of data and materials}

The data sets generated and / or analyzed during the current study are not publicly available due to the confidentia lity of the participants, but are available through the corresponding author upon rea sonable academic request. 


\section{Declarations}

\section{Ethics approval and consent to participate}

This work respects all bioethical criteria and has the approval of the Ethics Committee for research in Human Beings (CEISH) - of the San Francisco de Quito University.

\section{Consent for publication}

It does not a pplyto studies that do not publish M RI / CT / Rximages or physical examination photographs.

\section{Competing interests}

The authors declare not to have any interest conflicts.

\section{References}

1. Waal K, Kluckow M. Functional echocardiography; from physiology to treatment. Early Hum Dev. 2010;86(3):149-154. doi:10.1016/i.earlhumdev.2010.01.030

2. El-Khuffash AF, McNamara PJ. Neonatologist-performed functional echocardiography in the neonatal intensive care unit. Semin Fetal Neonatal Med. 2011;16(1):50-60. doi:10.1016/j.siny.2010.05.001

3. Evans N, Gournay V, Cabanas F, et al. Point-of-care ultrasound in the neonatal intensive care unit: international perspectives. Semin Fetal Neonatal Med. 2011;16(1):61-68. doi:10.1016/i.siny.2010.06.005

4. Moss S, Kitchiner DJ, Yoxall CW, Subhedar NV. Evaluation of echocardiography on the neonatal unit. Arch Dis Child Fetal Neonatal Ed. 2003;88(4):F287-F291. doi:10.1136/fn.88.4.f287

5. Sehgal A, Mehta S, Evans N, McNamara PJ. Cardiac sonography by the neonatologist: clinical usefulness and educational perspective. J Ultrasound Med. 2014;33(8):1401-1406. doi:10.7863/ultra.33.8.1401

6. Finan E, Sehgal A, Khuffash AE, McNamara PJ. Targeted neonatal echocardiography services: the need for standardized training and quality assurance. J Ultrasound Med. 2014;33(10):1833-1841. doi:10.7863/ultra.33.10.1833

7. Lopez L, Colan SD, Frommelt PC, et al. Recommendations for quantification methods during the performance of a pediatric echocardiogram: a report from the Pediatric Measurements Writing Group of the American Society of Echocardiography Pediatric and Congenital Heart Disease Council. J Am Soc Echocardiogr. 2010;23(5):465-577. doi:10.1016/j.echo.2010.03.019

8. Mertens L, Seri I, Marek J, et al. Targeted Neonatal Echocardiography in the Neonatal Intensive Care Unit: practice guidelines and recommendations for training. Writing Group of the American Society of Echocardiography (ASE) in collaboration with the European Association of Echocardiography (EAE) and the Association for European Pediatric Cardiologists (AEPC). J Am Soc Echocardiogr. 2011;24(10):1057-1078. doi:10.1016/i.echo.2011.07.014

\section{Author details}

Geyson Deley-M uñoz, M edical Doctor (MD) from the Latin American Christian University (Quito, Ecuador, 2007). Specialist in Pediatrics from the Pontificia Universidad Católica del Ecuador (Quito, Ecuador, 2013). Specia list in Neona tology from the San Francisco de Quito University (Quito, Ecuador, 2020). https:// orcid.org/0000-0002-6216-9819

2 Fabricio González-Andrade Doctor in M edicine and Surgery (MD) from the Universidad Central del Ecuador (2005), Specialist in Genetics from the University of Zaragoza (2006), Doctor [PhD] from the University of Zaragoza in the program of Anatomy, Pathology, Forensic and Legal Medicine and Toxicology (2012), Specialist in Internal Medicine from the Universidad de Guayaquil (2014). Email: fabriciogonzaleza@gmail.com ORCID: https://orcid.org/0000-0002-2091 9095.

9. Evans N, Kluckow M. Neonatology concerns about the TNE consensus statement. J Am Soc Echocardiogr. 2012;25(2):242-243. doi:10.1016/i.echo.2011.11.006

10. Bland JM, Altman DG. Statistical methods for assessing agreement between two methods of clinical measurement. Lancet. 1986;1(8476):307-310.

11. El-Khuffash A, Herbozo C, Jain A, Lapointe A, McNamara PJ. Targeted neonatal echocardiography ( $\mathrm{TnECHO}$ ) service in a Canadian neonatal intensive care unit: a 4-year experience. J Perinatol. 2013;33(9):687690. doi:10.1038/jp.2013.42

12. Corredera A, Rodríguez MJ, Arévalo $P$, Llorente $B$, Moro M, Arruza L. Ecocardiografía funcional en cuidados intensivos neonatales: experiencia en una unidad española a lo largo de un año [Functional echocardiography in neonatal intensive care: 1 year experience in a unit in Spain]. An Pediatr (Barc). 2014;81(3):167-173. doi:10.1016/i.anpedi.2013.11.026

13. O'Rourke DJ, El-Khuffash A, Moody C, Walsh K, Molloy EJ. Patent ductus arteriosus evaluation by serial echocardiography in preterm infants. Acta Paediatr. 2008;97(5):574-578. doi:10.1111/i.16512227.2008.00745.x

14. Australasian Society for Ultrasound in Medicine. CCPU in neonatal ultrasound. Available from https://www.asum.com.au/files/public/SoP/Current/Paediatrics_an d_Neo-Natal/Proficiency-and-Appropriate-Use-Statement-forNeonatal-Ultrasound-G1.pdf. [cited April 18, 2019]

15. Lai WW, Geva T, Shirali GS, et al. Guidelines and standards for performance of a pediatric echocardiogram: a report from the Task Force of the Pediatric Council of the American Society of Echocardiography. J Am Soc Echocardiogr. 2006;19(12):1413-1430. doi:10.1016/j.echo.2006.09.001

16. Critchley LA, Critchley JA. A meta-analysis of studies using bias and precision statistics to compare cardiac output measurement techniques. J Clin Monit Comput. 1999;15(2):85-91. doi:10.1023/a:1009982611386

17. Chew MS, Poelaert J. Accuracy and repeatability of pediatric cardiac output measurement using Doppler: a 20-year review of the literature. 
Intensive Care Med. 2003;29(11):1889-1894. doi:10.1007/s00134$\underline{003-1967-9}$

18. Clark SJ, Yoxall CW, Subhedar NV. Measurement of right ventricular volume in healthy term and preterm neonates. Arch Dis Child Fetal Neonatal Ed. 2002;87(2):F89-F94. doi:10.1136/fn.87.2.f89
19. Waal K, Kluckow M, Evans N. Weight corrected percentiles for blood vessel diameters used in flow measurements in preterm infants. Early $\begin{array}{lll}\text { Hum 2013;89(12):939-942 } & \end{array}$ doi:10.1016/j.earlhumdev.2013.09.017

20. Whitehall J. Echocardiography by a neonatologist. Arch Dis Child. 1999;80(6):580-581. doi:10.1136/adc.80.6.e579.

DOI: Digital Object Identifier PMID: PubMeD Identifier SU: Short URL

\section{Publisher's note}

The "Revista Ecuatoriana de Pediatría" remains neutral with regard to jurisdictional claims in published maps and institutional affiliations. 